\title{
Hsp90 Regulates NADPH Oxidase Activity and Is Necessary for Superoxide but Not Hydrogen Peroxide Production
}

\author{
Feng Chen,, ${ }^{1,2}$ Deepesh Pandey, ${ }^{2}$ Ahmed Chadli, ${ }^{3}$ John D. Catravas, ${ }^{2}$ Teng Chen, and David J.R. Fulton ${ }^{2}$
}

\begin{abstract}
The goal of this study was to identify whether heat-shock protein 90 (Hsp90) regulates the production of superoxide and other reactive oxygen species from the NADPH oxidases (Nox). We found that pharmacological and genetic inhibition of Hsp90 directly reduced Nox5-derived superoxide without secondarily modifying signaling events. Coimmunoprecipitation and bioluminescence resonance energy transfer studies suggest that the C-terminus of Nox5 binds to Hsp90. Long-term Hsp90 inhibition reduced Nox5 expression and provides further evidence that Nox5 is an Hsp90 client protein. Inhibitors of Hsp90 also reduced superoxide from Nox1, Nox2 (neutrophils), and Nox3. However, Nox4, which emits only hydrogen peroxide, was unaffected by Hsp90 inhibitors. Hydrogen peroxide production from the other Nox enzymes was not affected by short-term inhibition of Hsp90, but long-term inhibition reduced production of all reactive oxygen species coincident with loss of enzyme expression. Expression of chimeric Nox enzymes consisting of N-terminal Nox1 or Nox3 and C-terminal Nox4 resulted in only hydrogen peroxide formation that was insensitive to Hsp90 inhibitors. We conclude that Hsp90 binds to the C-terminus of Noxes1-3 and 5 and is necessary for enzyme stability and superoxide production. Hsp90 does not bind to the C-terminus of Nox4 and is not required for hydrogen peroxide formation. Antioxid. Redox Signal. 14, 2107-2119.
\end{abstract}

\section{Introduction}

$\mathbf{H}$ EAT-SHOCK PROTEIN 90 (Hsp90) are molecular chaperones that dynamically regulate the folding and structure of substrate proteins (31). The human genome encodes four Hsp90 proteins, the highly conserved cytosolic Hsp90AA (Hsp90 $\alpha$ ) and Hsp90AB (Hsp90 $\beta$ ), Hsp90B (grp94), which is present in the endoplasmic reticulum, and the mitochondrial Hsp90, TRAP1 (15). Cytosolic Hsp90s are very abundant proteins, representing over $1 \%$ of total cell protein and yet exhibit remarkable specificity by interacting with a specific clientele of just over 200 known proteins $(30,38)$. With the cooperation of cochaperones, dimeric Hsp90 utilizes ATP hydrolysis to influence the three-dimensional structure of clients and can modify or stabilize ligand-binding regions (30). Inhibitors of Hsp90, including geldanamycin (GA), 17allylamino-17-demethoxygeldanamycin (17-AAG), and radicicol (RAD), prevent Hsp90-dependent client protein folding by occupying the $\mathrm{N}$-terminal ATP binding site. The majority of Hsp90 substrates are transcription factors, kinases, or other signaling molecules such as the nitric oxide synthases and the ability of Hsp90 to interact with these signaling molecules and regulate cellular function has made it a viable target for pharmacological intervention. Inhibitors of Hsp90 have shown remarkable efficacy against various types of cancer (46), inflammation (6), cardiovascular disease (25), and acute lung injury (10). However, because Hsp90 interacts with a multitude of proteins, the exact mechanisms accounting for the efficacy of Hsp90 inhibitors remains elusive.

The NADPH oxidase (Nox) family of enzymes is comprised of seven members, Noxes (1-5) and Duoxes (1-2), and all conform to a basic structural paradigm consisting of two domains: a C-terminal NADPH-binding dehydrogenase domain and an $\mathrm{N}$-terminal transmembrane region that spans the membrane six times and incorporates two nonidentical heme groups (4). Nox enzymes utilize NADPH to synthesize superoxide and are a major source of cellular reactive oxygen species $(\mathrm{ROS})(7,18)$. Because of the inherent toxicity of ROS, the regulation of Nox enzymes has evolved a significant degree of complexity. The activities of Nox1-3 are controlled through a variety of protein:protein interactions that include p22phox, p67phox, p47phox, p40phox, Rac1, NOXO1, and NOXA1 (23, 37). Superoxide production from Nox 5 does not require these additional proteins and is instead regulated by intracellular calcium (3), by phosphorylation $(22,34)$, or via interaction with calmodulin (39). Nox4 binds p22phox (1) and exhibits a

\footnotetext{
${ }^{1}$ Department of Forensic Sciences, Xi'an Jiaotong University School of Medicine, Xi'an Shaanxi, P.R. China.

${ }^{2}$ Department of Pharmacology, Vascular Biology Center, Medical College of Georgia, Augusta, Georgia.

${ }^{3}$ Center for Molecular Chaperones/Radiobiology and Cancer Virology, Augusta, Georgia.
} 
constitutively active dehydrogenase domain (28). In contrast to the other Nox enzymes, which emit both superoxide and hydrogen peroxide, Nox4 produces little detectable superoxide but significant amounts of hydrogen peroxide $(19,26,33)$. As all Nox enzymes are proposed to synthesize superoxide as a primary metabolite, there is considerable interest in the mechanisms underlying the selective production of hydrogen peroxide by Nox4. Differences in subcellular location and/or the structure of Nox4 have been proposed as mechanisms, but it remains unclear how this occurs $(19,33,45)$.

There is considerable evidence that elevated ROS can contribute to the etiology and pathophysiology of certain cancers (41), inflammation (35), lung injury (8), and cardiovascular diseases (18). Inhibitors of Hsp90 have also shown great promise in the treatment of these maladies, but it is not yet known whether modulation of ROS production is one of the mechanisms underlying the effectiveness of these agents. Indeed, little is known about the ability of Hsp90 to influence ROS production. Inhibition of Hsp90 with GA has been reported to increase superoxide formation in endothelial cells. This effect is due to the ability of GA to exhibit redox cycling as well as cause the uncoupling of endothelial nitric oxide synthase $(5,13,32)$. In contrast, a role of Hsp90 in regulating the primary source of cellular ROS via the Nox enzymes is not yet known. This study will address two fundamental questions. The first is whether Hsp90 modulates the activity of Noxs. The second is whether Hsp90 is important in the ability of Nox enzymes to emit either superoxide or hydrogen peroxide.

\section{Materials and Methods}

\section{Cell culture and neutrophil isolation}

HEK 293 cells stably expressing Nox 5 and COS-7 cells were grown in Dulbecco's modified Eagle's medium (DMEM) and transfected with Lipofectamine2000 as previously described (12). Cells were exposed to different concentrations of GA (Biosciences), 17-AAG, and RAD for 0.5-12h. Blood was drawn from healthy volunteers via venipuncture of the antecubital vein and collected into 7-ml EDTA-treated tubes. Polymorphonuclear neutrophils were isolated by density gradient centrifugation using Lympholyte ${ }^{\circledR}$-poly. After centrifugation, the polymorphonuclear cells were isolated and diluted with an equal volume of culture medium and washed by centrifugation. The pellet consisted almost exclusively of polymorphonuclear granulocytes and was resuspended in media prior to measurements of ROS.

\section{DNA constructs}

cDNA for Nox $5 \beta$ (AF325189), Nox1, Nox3, and Nox4 have been previously described $(12,22,49)$. cDNA for Grp94 was obtained from Addgene. The myc-Nox5 C-terminal fragment construct was generated by PCR using the following primers: forward, 5'-CACCATGGAGCAGAAGCTGATCTCAGAGGA GGACCTGGGCGGCAGCTACCCATACGATGTTCCAGATT ACGCAGCCGTGTGCATCATG-3'; reverse, 5'-CTAGAAAT TCTCTTGGAAAAATC-3'. DNA sequences were confirmed by automated sequencing. Nox chimers were made with the following primers: Nox3:Nox4: 5'-ATAATTAGGTTCTGGC GAAGCAATAAGCCAGTCACC-3' based on that previously described by von Lohneysen et al. (45); Nox1-Nox4: 5'-
CTTTATATCTGTGAAAGGCTTTACAGGTATATCCGG-3' based on that described by Nisimoto et al. (28). For bioluminescence resonance energy transfer (BRET) studies, Hsp $90 \alpha$, Hsp90 $\beta$, and CDC37 CDS sequences were generated by PCR and subcloned into a modified pcDNA3.1 containing a Cterminal Rluc8 or Venus using the following primers: $5^{\prime}$ CATGGACGAGCTGTACAAGGGAGGCAGCCCTGAGGA AG-3', 5'-CATGGACGAGCTGTACAAGGGAGGCAGCCC TGAGGAAGTGCACCATG-3' and 5'-GTGCTGAAGAACG AGCAGGGAGGCAGCCCTGAGGAAGTGCACCATG3', and 5'-CATGGTGCACTTCCTCAGGGCTGCCTCCCTG CTCGTTCTTCAGCAC-3'.

\section{Measurement of ROS}

Cells were plated into white tissue culture-treated 96-well plates (ThermoLabsystems) at a density of $\sim 5 \times 10^{4}$ cells / well in DMEM with L-012 (400 $\mu$ M; Wako) for $10 \mathrm{~min}$ and luminescence was quantified over time using a Lumistar Galaxy (BMG) luminometer. The relative light units quantified reflect changes in the superoxide produced by Nox enzymes (22). Superoxide levels were also quantified by reduction of cytochrome $c$. Acetylated cytochrome $c(1 \mathrm{mg} / \mathrm{ml}$; Sigma) was incubated with cells in phenol-free medium in the presence and absence of superoxide dismutase (200 U/ml; Sigma) or RAD (40 $\mu \mathrm{M})$. Reduction of cytochrome $c$ was measured as an increase in absorbance at $550 \mathrm{~nm}$ and reported as absorbance ( $\lambda 550-540)$ and the amount of superoxide was determined by the Beer-Lambert law. Hydrogen peroxide was measured using the Amplex ${ }^{\circledR}$ Red assay with excitation at $544 \mathrm{~nm}$ and emission detection at $590 \mathrm{~nm}$. Cells were incubated for $10 \mathrm{~min}$ at $37^{\circ} \mathrm{C}$ with $50 \mu \mathrm{M}$ Amplex ${ }^{\circledR}$ Red and $0.125 \mathrm{U} / \mathrm{ml} \mathrm{HRP.} \mathrm{In} \mathrm{all}$ cases, background levels of hydrogen peroxide obtained from mock-transfected controls (lacZ) were subtracted from that obtained from cells expressing Nox enzymes.

\section{Antioxidant assay}

The generation of superoxide from NADH and phenazine methosulfate (PMS; Sigma) has been previously described (12, 14). In brief, PMS $(3.3 \mu \mathrm{M})$ was prepared in $50 \mathrm{mM}$ phosphate buffer containing $400 \mu M$ L-012 (pH 7.4; Wako) in the presence and absence of GA $(3 \mu M)$. NADH was injected at a final concentration of $78 \mu \mathrm{M}$ and luminescence was quantified over time.

\section{Isolated Nox5 enzyme activity assays}

COS-7 cells expressing Nox5 were lysed in a 3-(Nmorpholino)propanesulfonic acid (MOPS) (30 mM, pH 7.2)based buffer containing $\mathrm{KCl}(100 \mathrm{mM})$, Triton $(0.3 \%)$, and protease inhibitors (Sigma). Adherent cells were gently washed with lysis buffer, washed with $\operatorname{PBS}\left(4^{\circ} \mathrm{C}\right)$, resuspended in MOPS buffer with $0.3 \mathrm{mM}$ EGTA to remove residual calcium, sonicated at low power, and centrifuged at $14,000 \mathrm{rpm}\left(4^{\circ} \mathrm{C}\right)$. The supernatant was then aspirated, and the pellet was resuspended in MOPS buffer with mild sonication. The cell-free extract was aliquoted into buffers containing L-012 (400 $\mu \mathrm{M})$, $1 \mathrm{mM} \mathrm{MgCl} \mathrm{m}_{2}, 100 \mu \mathrm{M}$ FAD (Sigma), and $1 \mathrm{mM} \mathrm{CaCl}$. After a brief period of equilibration with or without agonists, reduced NADPH (Sigma) was injected to a final concentration of $200 \mu M$, and the production of ROS was monitored over time as previously described (22). 


\section{Transient knockdown of Hsp90 gene with siRNA}

siRNA targeting Hsp90 $\alpha$, Hsp90 $\beta$, and grp94 were obtained from Applied Biosystems. The target sequences for the siRNAs were Hsp90 $\alpha$, 5'-CCGACGAUAUUACUAAUGA-3'; Hsp90 $\beta$, 5'-CGACAAGAAUGAUAAGGCA-3'; and Grp94, 5'-GGAGUGAAGUUCGAUGAAA-3'. All siRNAs were transfected into HEK293 cells stably expressing Nox5 using siPORT ${ }^{\mathrm{TM}}$ Amine (Applied Biosystems).

\section{Coimmunoprecipitation and western blotting analysis}

Cells were lysed on ice in a lysis buffer containing $20 \mathrm{mM}$ Tris- $\mathrm{HCl}$ (pH 7.4), $100 \mathrm{mM} \mathrm{NaCl}, 1 \% \mathrm{NP}-40,10 \mathrm{mM} \mathrm{NaF}$, $1 \mathrm{mM} \mathrm{Na}_{3} \mathrm{VO}_{4}$, and $1 \%$ protease inhibitor cocktail (Sigma). SDS-PAGE and immunoblotting were performed using standard procedures (48). In brief, $500 \mu \mathrm{g}$ of cell extract was incubated for $2 \mathrm{~h}$ at $4^{\circ} \mathrm{C}$ with the relevant antibody: anti-HA (Roche Applied Science), anti-Flag (Sigma), anti-c-Myc (BD), anti-Hsp90 $\alpha$ (BD), anti-HSP90 $\beta$ (9), and anti-Grp94 (BD), and complexes were precipitated with A/G beads (Santa Cruz). Antigens were detached from the beads by incubating with SDS sample buffer at $95^{\circ} \mathrm{C}$ for $5 \mathrm{~min}$ and proteins were subjected to western blot analysis. Nox 5 phosphorylation statespecific antibodies to Ser ${ }^{490}$, $\mathrm{Thr}^{494}$, and $\mathrm{Ser}^{498}$ were generated by Pacific Immunology as previously described (22).

\section{BRET assay}

Forty-eight hours after transfection, cells were harvested in phenol-free DMEM (Sigma) and transferred to opaque 96-well microplates (Nunc). Benzyl-coelenterazine (coelenterazine h; $5 \mu M$; Nanolight Technologies) was injected immediately prior to measurement of emitted light using a photon-counting multimode plate reader (Mithras LB940; Berthold Technologies). The raw BRET signal (em 535/480) was calculated as the emission intensity at $520-545 \mathrm{~nm}$ divided by emission intensity at $475-495 \mathrm{~nm}$. Net BRET was this ratio minus the same ratio measured from cells expressing only the BRET donor (Rluc8).

\section{Statistical analysis}

Data are presented as means \pm SEM. Comparisons were made using two-tailed Student's $t$-test or analysis of variance with a post hoc test where appropriate. Differences were considered significant at $p<0.05$.

\section{Results}

\section{Structurally distinct inhibitors of Hsp90 potently suppress superoxide generated by Nox5}

To evaluate the effect of Hsp90 on the activity of Noxs and superoxide production, we incubated COS-7 cells expressing Nox5 with vehicle (ethanol) or the Hsp90 inhibitors, GA, 17AAG, and RAD, and measured superoxide using L-012 enhanced chemiluminescence. The Hsp90 inhibitors have different IC50s of $\sim 75,400$, and $270 \mathrm{n} M$. Thirty minutes of exposure to either GA, 17-AAG, or RAD potently inhibited superoxide production from unstimulated cells (Fig. 1A, B) and the cells stimulated with either ionomycin (Fig. 1C) or phorbol 12-myristate 13-acetate (PMA) (Fig. 1D). The ability of three different Hsp90 inhibitors to acutely suppress the superoxide signal was not related to changes in the expression of Nox 5 as shown by western blot (Fig. 1A, lower panel). The ability of GA to suppress Nox5-derived superoxide exhibited a clear dose-dependent relationship (Supplementary Fig. S3C; Supplementary Data are available online at www .liebertonline.com/ars). As higher concentrations of GA have been shown to exhibit redox cycling and increase superoxide formation $(5,13)$, we next investigated whether this was the case in cells that did not express a Nox. We found that although incubation with GA did lead to significantly higher superoxide formation in control cells (Fig. 5D), this was still considerably less than that observed in cells expressing Nox5 and contrary to its inhibitory actions on superoxide production in cells expressing Nox isoforms. To further assess whether GA is selectively inhibiting superoxide from Nox5 and to exclude the remote possibility that inhibitors of Hsp90 interfere with the ability of L-012 to detect superoxide, we next used additional superoxide-specific probes, superoxide dismutase-inhibitable cytochrome $c$ and 2-methyl-6-(4methoxyphenyl)-3,7-dihydroimidazo [1,2-a]pyrazin-3-one, hydrochloride (MCLA). Results obtained with cytochrome $c$ (Fig. 1B) and MCLA (Supplementary Fig. S1A) were consistent with those obtained with L-012 and show that Hsp90 inhibitors potently suppress Nox-derived superoxide. The specificity of L-012 and MCLA for superoxide-generated signals is shown in Supplementary Figure S1A and B.

\section{Hsp90 inhibitors directly inhibit Nox5 enzyme activity}

To exclude the possibility that GA could be acting as a nonspecific scavenger of superoxide, we next examined whether GA can influence the nonenzymatic production of superoxide. Superoxide production from PMS was not affected by GA, suggesting that it does not act as a scavenger of superoxide (Fig. 2A). The calcium sensitivity of Nox5 is regulated by protein kinase C (PKC)-dependent phosphorylation (22), and as Hsp90 actively participates in kinase signaling, we also investigated whether it influences Nox 5 phosphorylation. Hsp90 inhibitors did not influence the basal or PMA-stimulated phosphorylation of Nox5 at S490, T494, and S498 (Fig. 2B). To exclude other factors such as calcium levels and NADPH levels, we next assessed the effect of Hsp90 inhibitors on Nox5 activity in an isolated enzyme activity with supplemental cofactors. This was achieved using partially purified Nox5 with the addition of cofactors FAD, calcium, and NADPH (arrow) to initiate superoxide production. GA dose-dependently inhibited Nox5-derived superoxide (Fig. 2C). These findings rule out the possibility that primary mechanism of Nox5 inhibition by Hsp90 inhibitors is through reduction in other signaling events that are critical to support Nox activity.

\section{Genetic inhibition of $\mathrm{Hsp} 90 \alpha$ and $\mathrm{Hsp} 90 \beta$, but not Grp94, reduces Nox5-derived superoxide}

To support the pharmacological findings shown in Figure 1, we next tested whether transient knockdown of Hsp90 gene expression could influence the activity of Nox5.

The selective silencing of Hsp90 $\alpha$, Hsp90 $\beta$, and GRP94 using siRNA for each isoform is shown in Figure 3A. Knockdown of the cytosolic Hsp90s (Hsp90 $\alpha$ and Hsp90 $\beta$ ) inhibited Nox5-derived superoxide (Fig. 3B). Knockdown of both Hsp $90 \alpha$ and $\beta$ isoforms produced a dose-dependent inhibition of Nox 5 activity consistent with that seen with pharmacological inhibitors (Supplementary Fig. S3D). Knockdown 
A

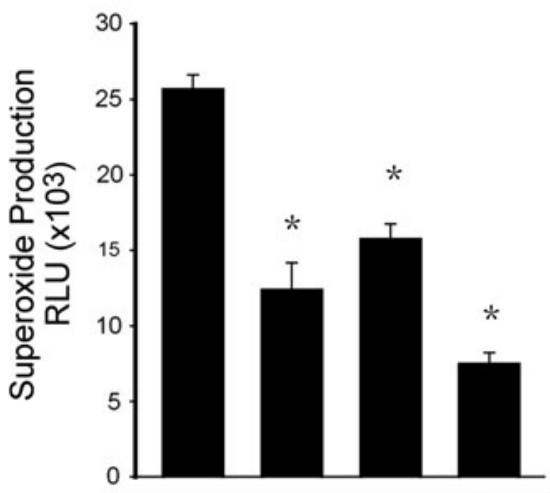

IB: HA-Nox5

IB: GAPDH

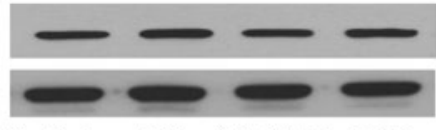

Vehicle GA 17-AAG RAD

C

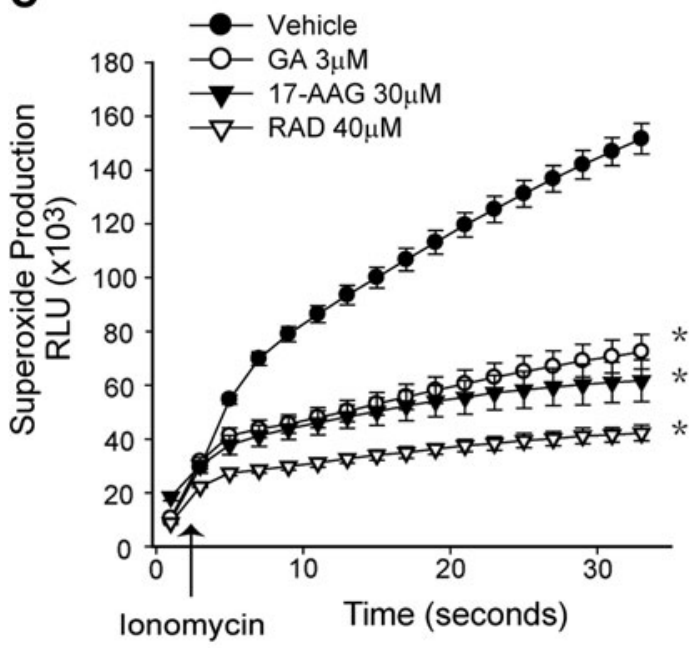

B
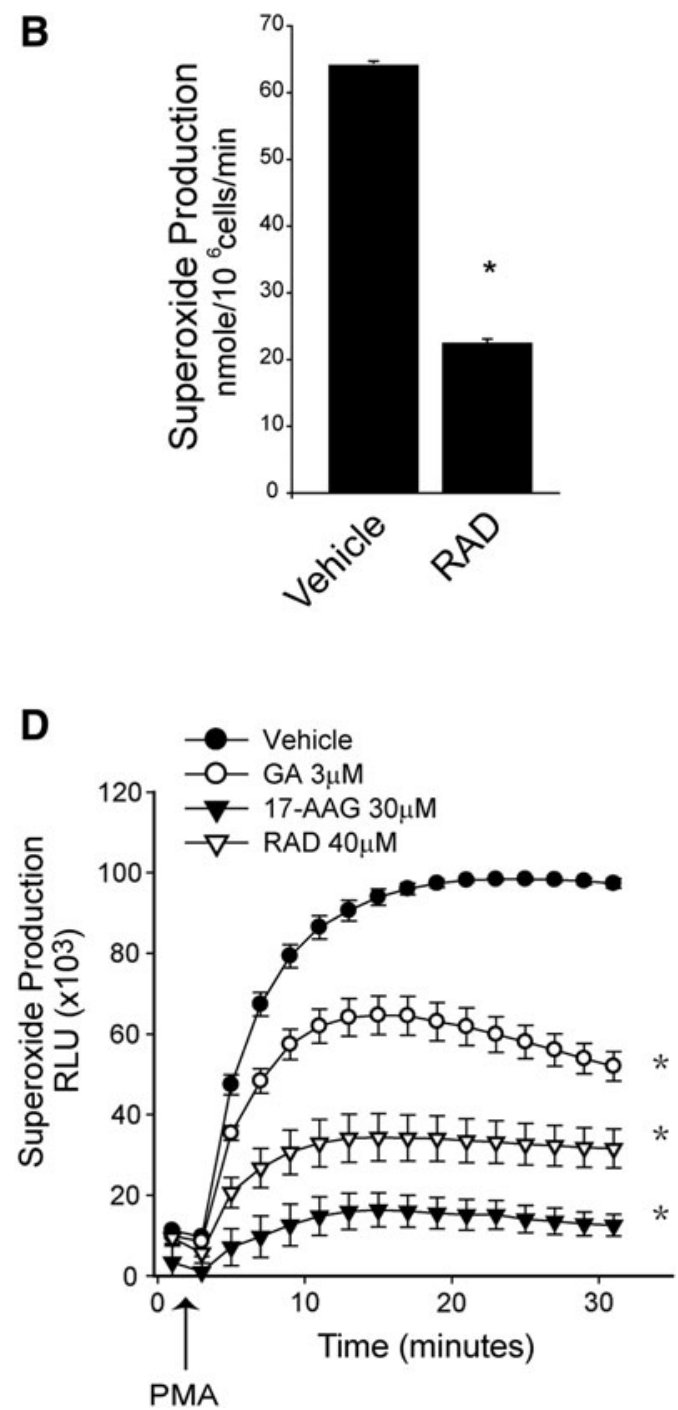

FIG. 1. Structurally distinct inhibitors of heat-shock protein 90 (Hsp90) suppress NADPH oxidase 5 (Nox5) activity. Superoxide production was monitored in COS-7 cells transfected with HA-Nox5. (A) Unstimulated or basal superoxide release in the presence and absence of Hsp90 inhibitors as detected by L-012. Cells were incubated with vehicle (EtOH) or geldanamycin (GA, $3 \mu M$ ), 17-allylamino-17-demethoxygeldanamycin (17-AAG, $30 \mu M$ ), and radicicol (RAD, 40 $\mu M$ ) for $30 \mathrm{~min}$. Lower panel: Relative expression of Nox5 and GAPDH in total cell lysates. (B) Superoxide release in the presence and absence of RAD $(40 \mu \mathrm{M})$ as measured by absorbance of reduced cytochrome $c$. (C, D) Superoxide release from cells stimulated with ionomycin or phorbol 12-myristate 13-acetate (PMA) as measured by L-012. Arrow indicates injection of ionomycin $(1 \mu M)$ or PMA $(100 \mathrm{nM})$. Results are presented as mean \pm SEM $(n=4-6) ;{ }^{*} p<0.05$, versus vehicle.

of the endoplasmic reticulum Hsp90, Grp94, did not significantly reduce the level of Nox5-derived superoxide. To test whether Hsp90 has a direct effect on Nox5 activity, purified Hsp90 was added to an isolated Nox5 enzyme activity assay. The addition of Hsp90 protein significantly increased Nox5derived superoxide production (Fig. 3C). Coexpression of Nox5 with Grp94 failed to increase Nox5-derived superoxide (Supplementary Fig. S2). Collectively, these data demonstrate that the cytosolic Hsp90s (Hsp90 $\alpha$ and Hsp90 $\beta$ ), and not Grp94, are important for the regulation of Nox5 activity.

\section{Hsp90 physically associates with Nox5}

To address whether Hsp90 physically associates with Nox5, we performed a coimmunoprecipitation experiment. Because Nox 5 resides in detergent-resistant membrane frac- tions and requires SDS in excess of $1 \%$ for solubilization, which precludes coimmunoprecipitation (22), we generated a Myc-tagged construct expressing the cytoplasmic C-terminal region (residues 398-719) of Nox5 (Fig. 4A). In lysates from COS-7 cells expressing Myc-Nox5 (398-719), we immunoprecipitated with anti-Myc and immunoblotted for Myc and associated Hsp90 $\alpha$ and $\mathrm{Hsp} 90 \beta$. We found that the Cterminal region of Nox 5 bound both Hsp90 $\alpha$ and $\beta$ (Fig. 4B). We next performed the converse experiment by immunoprecipitating $\mathrm{Hsp} 90 \alpha$ and $\beta$ and immunoblotting for bound Myc-Nox5 (398-719). We found that both Hsp90 $\alpha$ and $\beta$ are present in immune complexes together with the Cterminal region of Nox5 (Fig. 4C). However, the C-terminal fragment of Nox5 is not bound to cellular membranes and thus is likely to exhibit a diffuse subcellular localization. Previously we have shown that Nox5 resides in specific 
FIG. 2. Hsp90 inhibitors directly affect Nox 5 enzymatic activity and do not influence Nox 5 phosphorylation or superoxide dismutation. (A) Superoxide was generated chemically by the addition of NADH (arrow) to phenazine methosulfate (PMS) and was measured using L-012 chemiluminescence in the presence and absence of GA $(3 \mu \mathrm{M})$. (B) COS-7 cells expressing Nox 5 were treated with vehicle or GA for $30 \mathrm{~min}$. in the presence or absence of PMA (100 nM) and phosphorylation of Nox5 at $\operatorname{Ser}^{490}, \operatorname{Thr}^{494}$, and Ser $^{498}$ were determined by western blot using phosphorylation state-specific antibodies. Representative blots from three independent experiments are shown. (C) Superoxide release from an isolated Nox5 activity assay. Partially purified Nox5 was incubated with calcium $(1 \mathrm{mM})$ and FAD $(100 \mu M)$ and enzyme activity was initiated with NADPH $(200 \mu M)$ in the presence and absence of varying concentrations of GA. Superoxide was measured using L-012. Arrow indicates the injection of NADPH. Results are presented as mean \pm SEM $(n=6) ;{ }^{*} p<0.05$, versus vehicle.

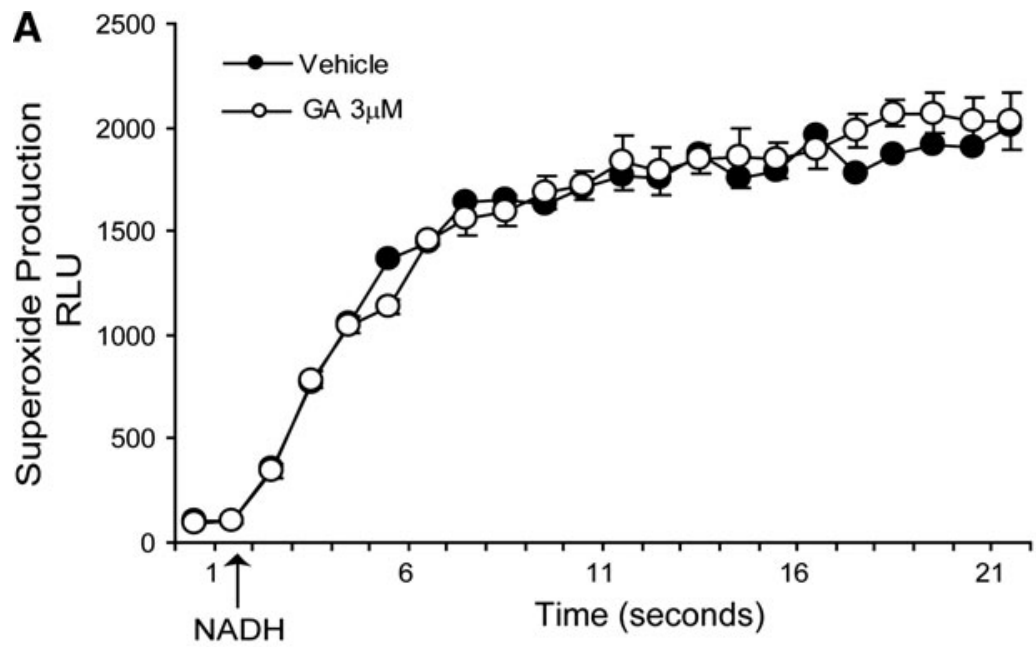

B

IB: Nox5 P-S490

IB: Nox5 P-T494

IB: Nox5 P-S498

IB: HA Nox 5

$\mathrm{GA}(3 \mu \mathrm{M})$
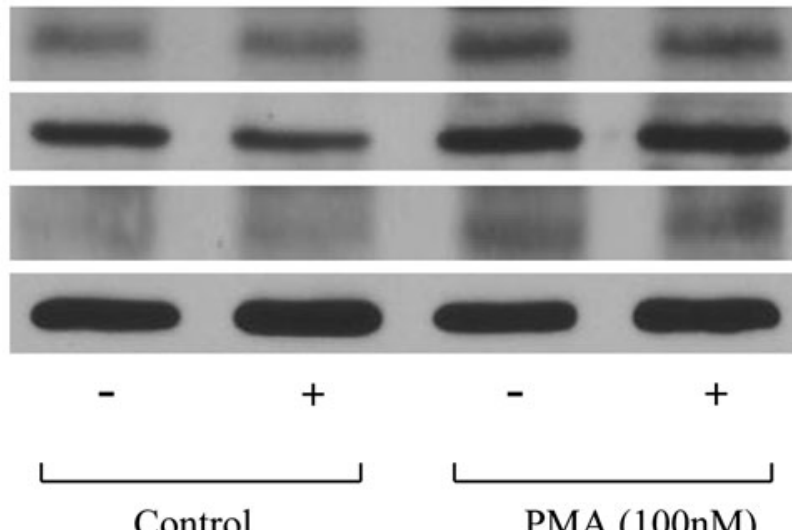

Control

PMA (100nM)
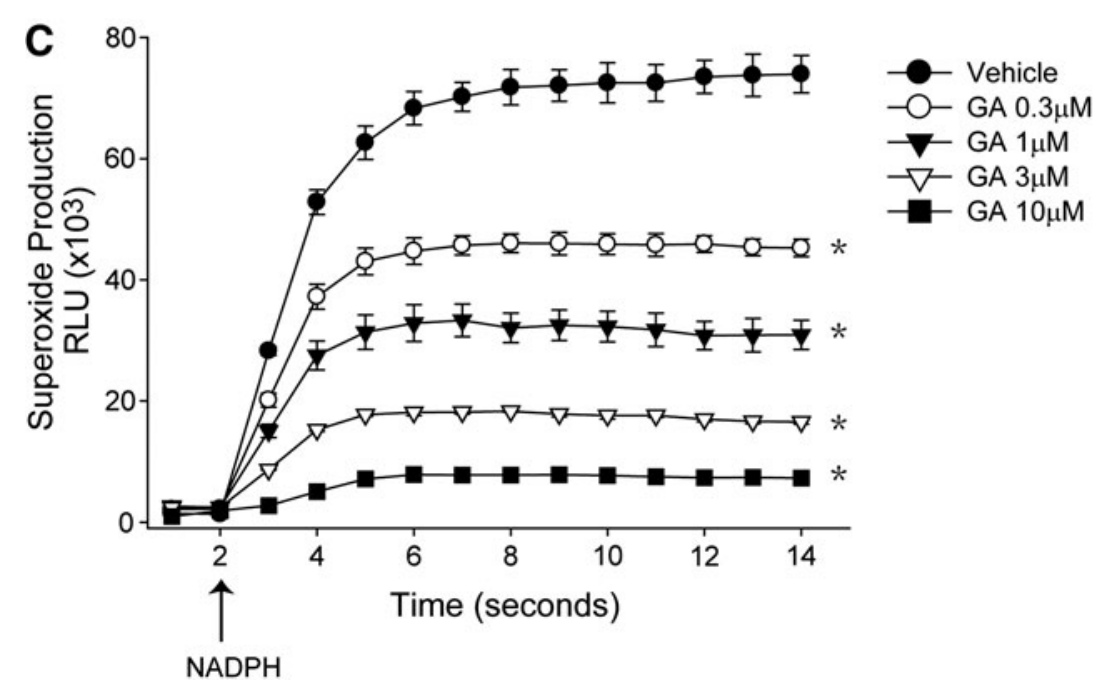

membrane regions of the ER, and thus, we next sought to investigate whether Hsp90 associates with full-length, ER-targeted Nox5 in intact cells. This was achieved by measuring the energy transfer between Hsp90 and Nox5, a measure of proximity, in intact cells using BRET (2). We generated fusion proteins encoding the BRET acceptor Venus coupled to Nox5 and the BRET donor Renilla luciferase (RLUC) to the amino terminus of Hsp90 (Fig. 4E). The coexpression of
Hsp90-Venus with Nox5-Rluc dose-dependently increased the BRET ratio (Fig. 4F). These findings were similar to those obtained with a positive control, the Hsp90 cochaperone CDC37 (Fig. 4G). Many Hsp90 client proteins are stabilized by Hsp90 and degrade in the presence of Hsp90 inhibitors (30). We did not observe an acute effect of Hsp90 inhibitors on Nox5 expression levels (Fig. 1A), although this would be unlikely given the $30 \mathrm{~min}$ time frame. Therefore, we next 
A

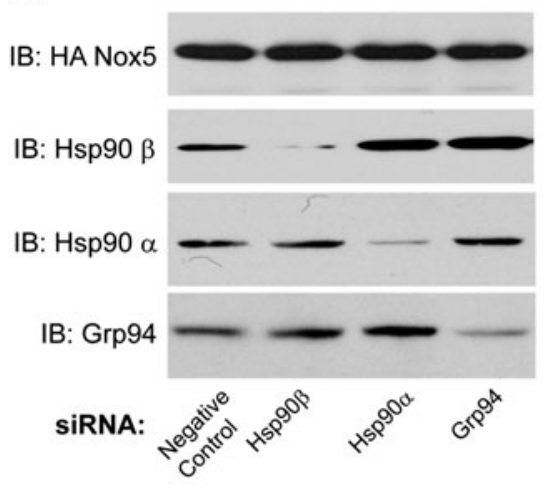

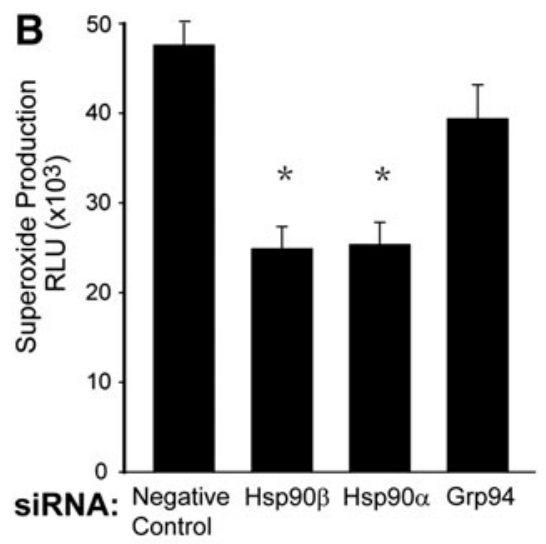

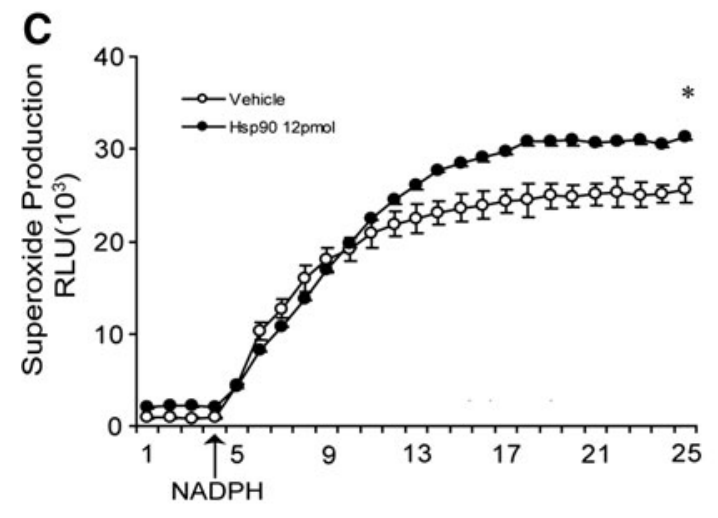

FIG. 3. Expression of Hsp90 $\alpha$ and Hsp90及, but not Grp94, is necessary for Nox5-derived superoxide. HEK293 cells stably expressing Nox5 were transfected with negative control siRNA or siRNA targeting Hsp90 $\alpha$, Hsp90 $\beta$, or Grp94 and basal superoxide was measured using L012. (A) Western blot showing the relative expression of Hsp90 $\alpha$, Hsp $90 \beta$, and Grp94 versus GAPDH. (B) Relative levels of superoxide from cells treated with Hsp $90 \alpha$, Hsp90 $\beta$, and Grp94 siRNA. (C) Nox5 activity was determined in an isolated enzyme activity assay in the presence and absence of supplemental Hsp90. Arrow indicates the injection of NADPH. Results are presented as mean \pm SEM $(n=4-6) ;{ }^{*} p<0.05$, versus vehicle. tested whether the expression of Nox 5 is influenced by longterm exposure $(12 \mathrm{~h})$ of cells to Hsp90 inhibitors. We found that long-term exposure to Hsp90 inhibition caused a dosedependent decrease in the expression of Nox5 (Fig. 4D).

\section{Hsp90 inhibitors influence the activity of other Nox enzymes with the exception of Nox4}

We next tested whether Hsp90 inhibitors could influence the activity of other Nox isoforms. In addition to Nox5 (Fig. $5 \mathrm{~A})$, we found that GA was also effective at inhibiting superoxide production from cells expressing Nox1 or Nox3 and their activating subunits NoxO1 and NoxA1 (Fig. 5B, C). The structurally distinct inhibitor of Hsp90, RAD, dosedependently suppressed superoxide production (Fig. 5E). In human neutrophils, which were employed as a source of Nox2, we found that GA (Fig. 5F) and RAD (Fig. 5G) dosedependently reduced PMA-induced superoxide formation. However, in cells expressing Nox4, an elevation of superoxide levels above control-transfected cells (lacZ) could not be detected (Fig. 5D). As Nox4 preferentially emits detectable hydrogen peroxide, we next evaluated whether Hsp90 inhibitors influence hydrogen peroxide release from Nox enzymes. To our surprise, we found that acute $(1 \mathrm{~h})$ incubation with GA did not affect hydrogen peroxide formation from Nox5, Nox4, Nox1, or Nox3 (Fig. 6A-D, left panel). Hydrogen peroxide production was refractory to higher concentrations of GA (Supplementary Fig. S3A-C) and RAD (Fig. 6E). However, longer $(12 \mathrm{~h})$ incubation times with $\mathrm{GA}$, which reduces the expression of Nox5 (Fig. 4D), decreased hydrogen peroxide production from Nox5, Nox3, and Nox1 but not from Nox4 (Fig. 6A-D, right panel). Long-term exposure to Hsp90 inhibitors also reduced the agonist-stimulated production of hydrogen peroxide (Supplementary Fig. S4). Hydrogen peroxide formation was absent in control-transfected cells, and in cells expressing Nox1, 3, 4, and 5, the increased signal was virtually abolished by inclusion of the hydrogen peroxide scavenger catalase (Supplementary Fig. S1C).

FIG. 4. Hsp90 binds to the C-terminal domain of Nox5 and is important for enzyme stability. (A) A schematic diagram depicting the generation of a Myc-tagged C-terminal fragment of Nox5 (Myc-Nox5 C-TERM). (B) COS-7 cells were transfected with the Nox5 C-terminal construct, and $48 \mathrm{~h}$ later, cell lysates were immunoprecipitated using either a negative isotype control mouse immunoglobulin (IgG) or a monoclonal antibody against c-Myc. Immune complexes were immunoblotted for Myc, Hsp90 $\alpha$, or Hsp90 $\beta$. (C) The reverse experiment was performed and lysates from Myc-Nox5 CTERM-transfected COS cells were immunoprecipitated using control IgG or anti-Hsp90 $\alpha$ or -Hsp90 $\beta$ antibodies and immunoblotted with anti-c-Myc. (D) Cells expressing Nox5 were treated with GA at the indicated concentrations for $12 \mathrm{~h}$ and cell lysates were immunoblotted for HA-Nox5 versus GAPDH. (E) Schematic of constructs used for bioluminescence resonance energy transfer (BRET) studies. (F, G) COS-7 cells were transfected with different ratios of Rluc-Hsp90:Venus-Nox5 or Rluc-Hsp90:Venus-CDC37 (shown on $x$-axis) and incubated with $5 \mu M$ coelenterazine $\mathrm{h}$, and luminescence light-emission acquisition was performed immediately. Background subtracted BRET ratio is shown on the $y$-axis. Results are presented as mean \pm SEM $(n=4-6)$. 
Resistance to Hsp90 inhibition is encoded within the C-terminus of Nox4

In Figure $4 \mathrm{~A}-\mathrm{C}$, we showed that the $\mathrm{C}$-terminal region of Nox 5 binds to Hsp90. As Nox4 is resistant to both acute and long-term inhibition of Hsp90, we next examined whether this was a property encoded within its C-terminus. To achieve this, we generated a series of Nox chimeras consisting of the N-terminal region of Nox1 or Nox3 and the C-terminal region of Nox4 (Fig. 7A). The expression of chimeric enzymes in

A

Myc

B

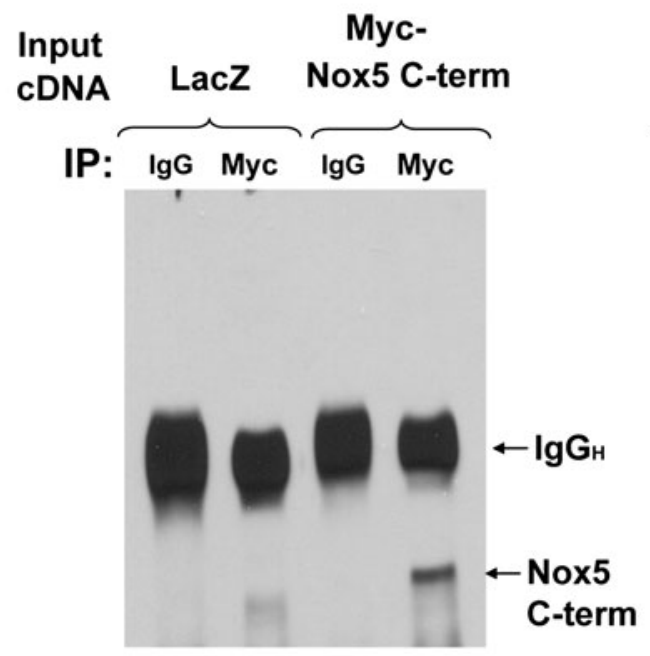

IB: Myc

C Input cDNA IP:

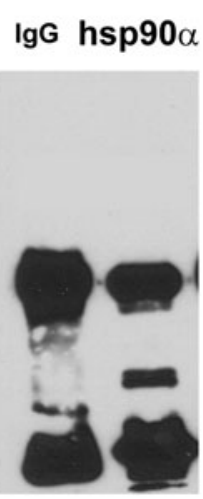

IB: Myc

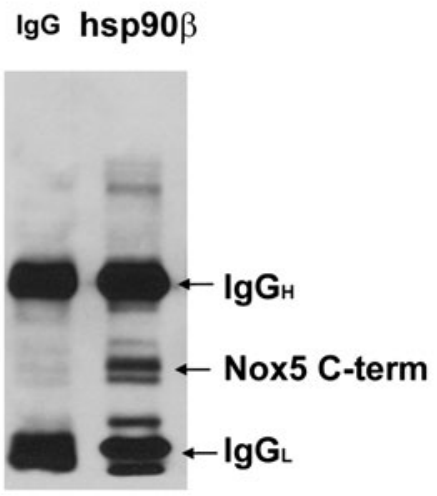

IB: Myc
Myc-

\section{LacZ Nox5 C-term}
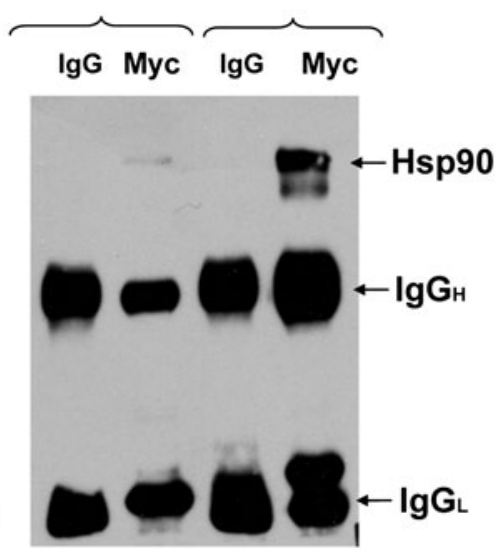

IB: hsp90 $\beta$
Myc-

\section{Nox5 C-term}

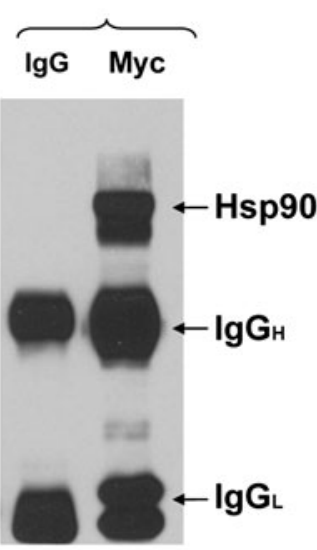

IB: hsp90 $\alpha$
E
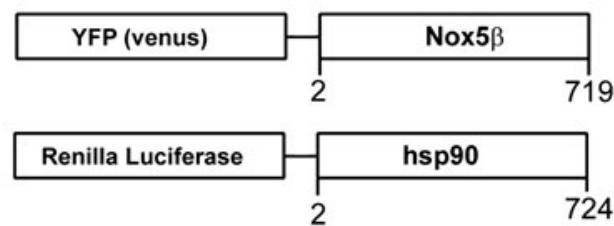

F
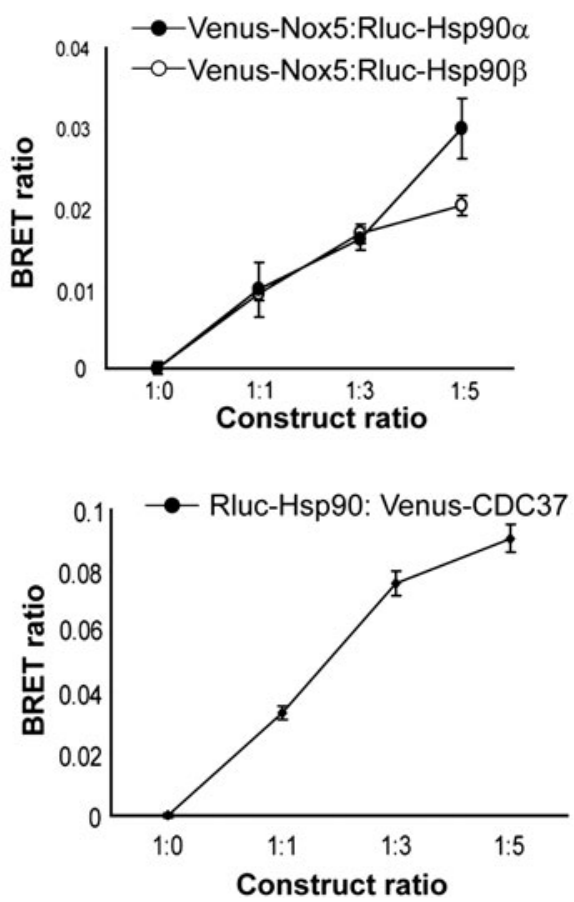

G Construct ratio
D

IB: anti HA-Nox5

IB: anti GAPDH

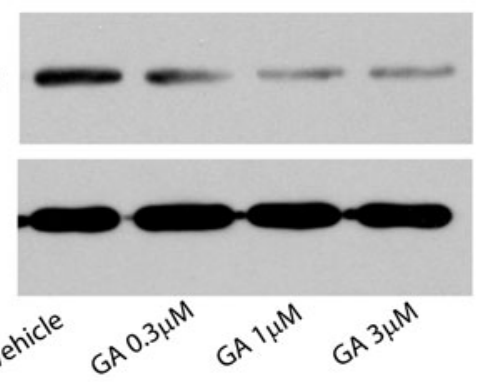



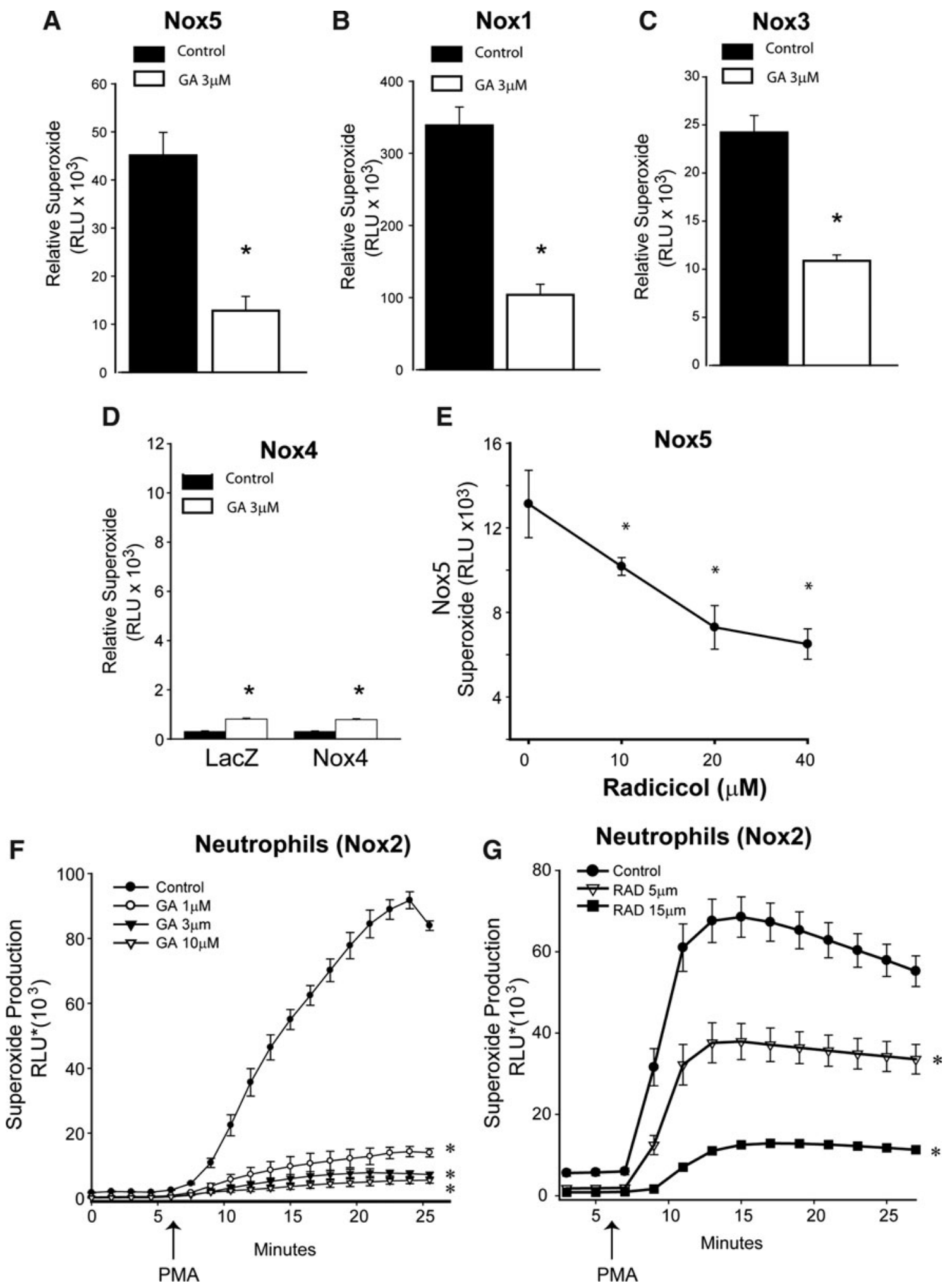

FIG. 5. Superoxide production from the other Nox isoforms, with the exception of Nox4, is sensitive to Hsp90 inhibition. COS-7 cells were singularly transfected with Nox 5 or Nox4 or cotransfected with Nox1 or Nox3 together with NOXO1 and NOXA1. (A-D) Cells were treated with either vehicle or GA for $30 \mathrm{~min}$ and superoxide release was measured by L-012. (E) Superoxide release from Nox5-transfected cells in the presence of increasing concentrations of RAD. (F, G) Freshly isolated human neutrophils were exposed to GA or RAD for $30 \mathrm{~min}$ and superoxide release was measured using L-012. Results are presented as mean $\pm \operatorname{SEM}(n=4-6) ;{ }^{*} p<0.05$, versus vehicle. 

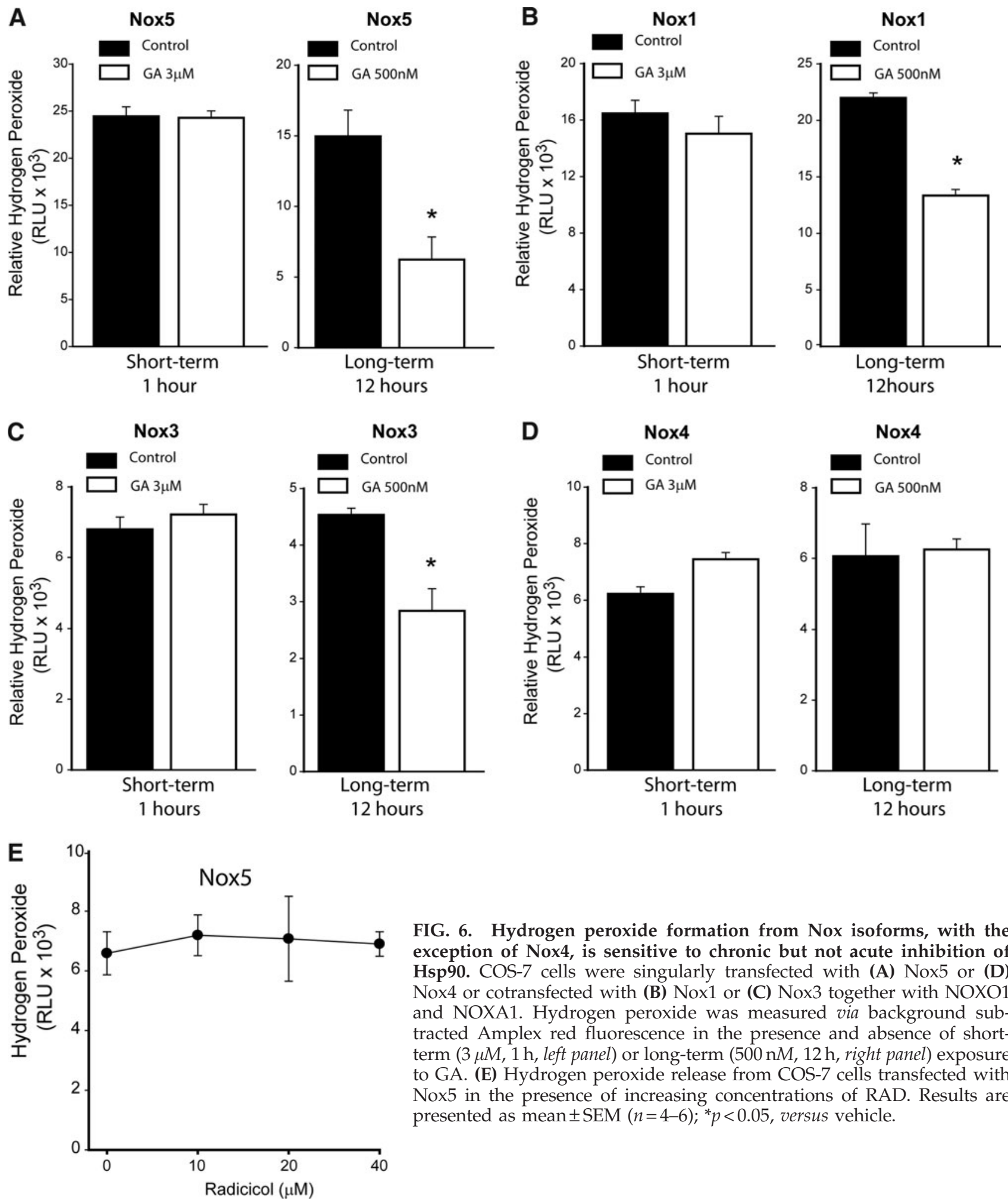

FIG. 6. Hydrogen peroxide formation from Nox isoforms, with the exception of Nox4, is sensitive to chronic but not acute inhibition of Hsp90. COS-7 cells were singularly transfected with (A) Nox5 or (D) Nox4 or cotransfected with (B) Nox1 or (C) Nox3 together with NOXO1 and NOXA1. Hydrogen peroxide was measured via background subtracted Amplex red fluorescence in the presence and absence of shortterm $(3 \mu M, 1 \mathrm{~h}$, left panel) or long-term ( $500 \mathrm{nM}, 12 \mathrm{~h}$, right panel) exposure to GA. (E) Hydrogen peroxide release from COS-7 cells transfected with Nox5 in the presence of increasing concentrations of RAD. Results are presented as mean \pm SEM $(n=4-6) ;{ }^{*} p<0.05$, versus vehicle.

COS-7 cells resulted in the detection of hydrogen peroxide but not superoxide (Fig. 7B, C). In contrast, the positive control Nox1 in the presence of NoxO1 and NoxA1 produced both hydrogen peroxide and superoxide. Long-term (12 h) incubation of cells expressing Nox1 with the Hsp90 inhibitor, GA, reduced hydrogen peroxide formation as we have previously shown. However, hydrogen peroxide production from cells expressing the chimeric Nox1 and Nox $3 \mathrm{~N}$-terminal domains fused to the C-terminus of Nox4 was unaffected by inhibition of Hsp90. As a further control, we also generated the reverse chimeras (Nox4:Nox1 and Nox4:Nox3) and cotransfected them together with NOXO1 and NOXA1. The addition of 
A

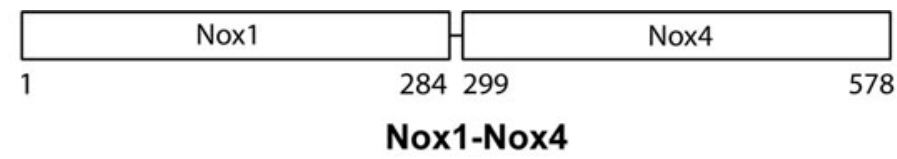

\begin{tabular}{|lll|}
\hline & Nox3 & Nox4 \\
\hline 1 & 288 & 305 \\
Nox3-Nox4 & &
\end{tabular}
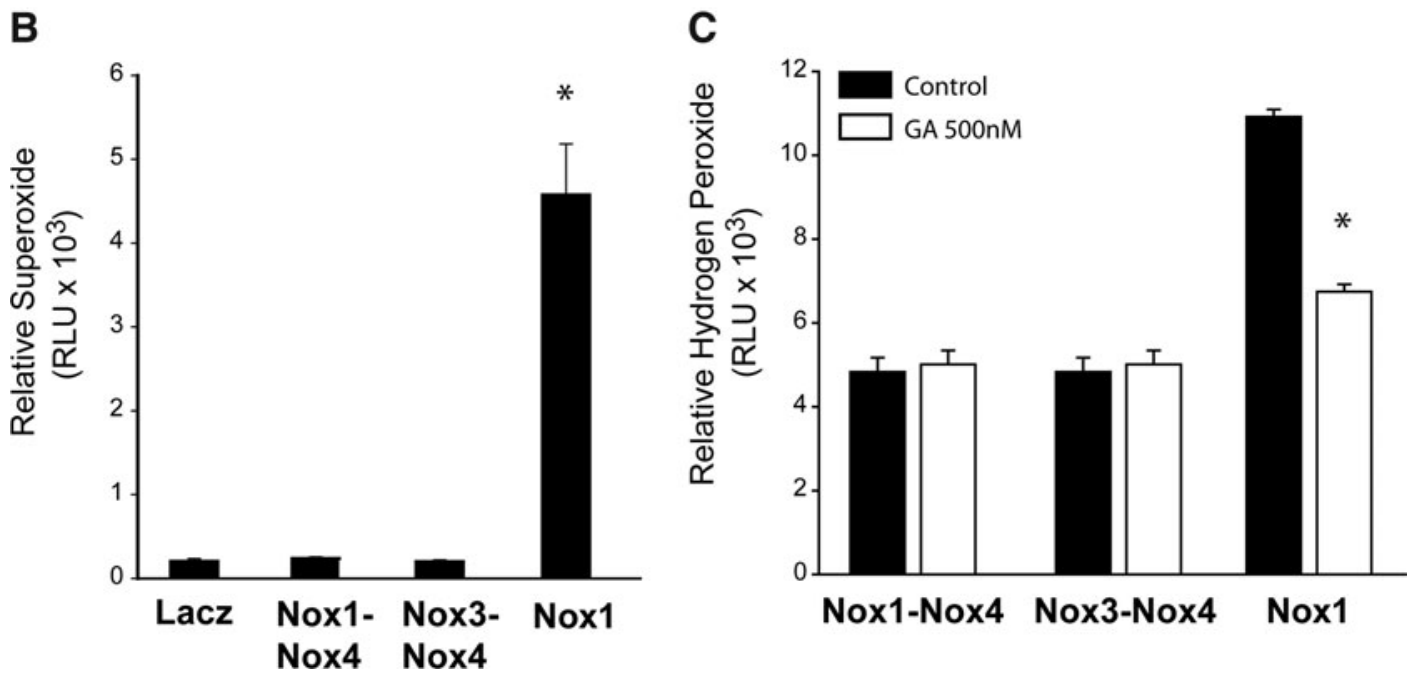

FIG. 7. The C-terminal of Nox enzymes is important for Hsp90-dependent production of superoxide and enzyme stability. (A) A schematic diagram outlining the generation of chimeric Nox enzymes consisting of the N-terminus from Nox1 or Nox3 fused to the C-terminus of Nox4. (B) Superoxide release from COS-7 cells expressing Nox1-4, Nox3-4 singularly, and Nox1 together with NOXO1 and NOXA1. (C) Hydrogen peroxide release from COS-7 cells expressing only Nox1-4, Nox3-4, or Nox1 together with NOXO1 and NOXA1 in the presence or absence of long-term (12 h) treatment with GA. Results are presented as mean $\pm \operatorname{SEM}(n=4) ;{ }^{*} p<0.05$, versus lacZ control or vehicle.

Nox1 or Nox3 to the C-terminus of Nox4 restored sensitivity to the long-term exposure to GA (500 $\mathrm{nM}, 12 \mathrm{~h})$ and reduced hydrogen peroxide production (Supplementary Fig. S5).

\section{Discussion}

The goals of this study were twofold. The first was to determine whether Hsp90 is involved in the production of superoxide from Noxs. To this end we first employed Nox5, a prototypical Nox enzyme that does not require the assembly of other protein subunits for activation. We found that inhibition of Hsp90 potently attenuated both basal and stimulated Nox5-derived superoxide production. This was observed with three structurally distinct pharmacological inhibitors and also with a genetic approach using siRNA to silence the cytosolic Hsp90 $\alpha$ and $\beta$. The effects of the Hsp90 inhibitors were not limited to the Nox5 isoform, and superoxide production from Nox1, Nox2 (neutrophils), and Nox3 was susceptible to Hsp90 inhibition. Further, we found that Nox5 binds to Hsp90 and coimmunoprecipitation studies with the soluble C-terminal region of Nox5 suggest that Hsp90 interacts with the dehydrogenase domain of Nox5. These findings are strengthened by the ability of chronic inhibition of Hsp90 to reduce the expression of Nox5, a result consistent with Nox 5 being a substrate or client protein of Hsp90. The ability of Hsp90 to enhance, and inhibitors of Hsp90 to reduce, superoxide production in an isolated enzyme activity assay suggests that Hsp90 has direct actions on Nox enzyme function.

Our second goal was to determine whether Hsp90 influences hydrogen peroxide formation from the Nox enzymes. Previous studies have shown that Nox enzymes, with the exception of Nox4, produce a combination of superoxide and hydrogen peroxide $(19,26,33)$. The enzymatic mechanisms underlying this are poorly understood and it has generally been assumed that hydrogen peroxide formation was due to the inexorable enzymatic or spontaneous dismutation of superoxide. The discovery that Nox4 emits only hydrogen peroxide has added a level of complexity to this theory $(19,26$, 33). A particularly unexpected finding of this study was that inhibition of Hsp90 selectively reduced superoxide but not hydrogen peroxide production. A reduction in hydrogen peroxide production can be observed with longer exposure to Hsp90 inhibitors, but this is commensurate with loss of enzyme expression. The activity of Nox4, which produces only hydrogen peroxide, is resistant to both acute and chronic inhibition of Hsp90. Chimeric Nox enzymes comprised of the N-terminus of Nox1 or Nox3 and the C-terminus of Nox4 produce only hydrogen peroxide and are refractory to longterm inhibition of Hsp90. One explanation for this finding is that Hsp90 binds to the C-terminus of Nox1, 2, 3, and 5 and is necessary for superoxide production. However, Hsp90 does not bind to the C-terminus of Nox4 and Hsp90 is not required for hydrogen peroxide formation. 
Previous studies have shown that inhibition of Hsp90 increases ROS formation in endothelial cells. This can be attributed to the ability of the Hsp90 inhibitor GA to exhibit redox cycling (5) and also to the uncoupling of nitric oxide synthases $(13,32,36)$. In our study, we have been mindful of the potential for nonspecific actions of pharmacological inhibitors of Hsp90 and have therefore employed a comprehensive approach by using three structurally distinct inhibitors and siRNA. We have found consistent inhibition of superoxide formation from cells expressing Noxes1, 3, and 5 and also from human neutrophils, which express Nox2 endogenously. In a macrophage cell line, Vega and De Maio reported that acute exposure to GA did not influence superoxide formation as measured by nitroblue tetrazolium (43). However, the reduction of nitroblue tetrazolium is not a reliable measure of Nox-derived superoxide, as it can be reduced directly by flavoproteins including both nitric oxide synthases and Noxs (42).

Because Nox5 is localized to the endoplasmic reticulum (22), we were interested in whether a paralog of Hsp90 (Grp94, HSP90B1) could modulate Nox-dependent superoxide production. Grp94 is also restricted to the endoplasmic reticulum, provides cellular protection from oxidative stress (24), and is sensitive to Hsp90 inhibitors (11). However, the silencing of Grp94 did not modify superoxide levels in cells expressing Nox5 and therefore cannot account for the actions of the pharmacological inhibitors of Hsp90 on Nox5. In a previous study, we showed that an inhibitor of arginine methylation potently suppressed Nox-derived superoxide in an unanticipated action as an antioxidant (12). Therefore, we also assessed whether GA was possibly scavenging superoxide and found no evidence for such ability. As Hsp90 client proteins are involved in signal transduction, it was also possible that Hsp90 inhibitors impair the activity of protein kinases responsible for the activation of Nox 5 and other Noxes. However, the phosphorylation of Nox5 at key phosphorylation sites, S490, T494, and S498, was unaffected by inhibition of Hsp90 and cannot account for its inhibitory actions.

The mechanisms by which Hsp90 selectively influences the production of superoxide from Noxes1, 2, 3, and 5 remain unresolved. Hsp90 is required in the catalytic activities of many other heme-containing proteins including the nitric oxide synthases $(5,16,47)$, soluble guanylate cyclase $(44)$, the kinase EIF2AK1 (40), the transcription factor Hap1 (20), and cytochrome P450 (27). Rather than having a uniform action on these client proteins, the actions of Hsp90 are diverse. Hsp90 can influence protein stability $(27)$, heme binding $(5,20)$, and protein:protein interactions $(17,44)$. However, a common theme is that Hsp90 influences a conformational change within client proteins to enable specific functions such as ligand binding (29). Thus, it is likely that by modulating the conformation of unstable regions within the C-terminal domains of Noxes1, 2, 3, and 5, Hsp90 facilitates superoxide production. Nox4, which does not appear to be affected by Hsp90, does not possess these unstable regions, is unaffected by Hsp90 inhibition, and produces only hydrogen peroxide. It is also worth noting that activators of PKC, such as PMA, also potently increase the expression of Hsp90 (21). Thus, in addition to acutely activating Nox enzymes by phosphorylation of subunits or the direct phosphorylation of Nox5, the activation of PKC pathways could in the long term promote further amplification of superoxide production via increased expression of Hsp90.
Hsp90 inhibitors are currently being used to treat various cancers and inflammatory conditions, diseases in which ROS are elevated, and thought to play a significant role. Thus, the ability of Hsp90 inhibitors to prevent ROS formation may, at least in part, explain the effectiveness of these agents. Conversely, it also possible that Hsp90 inhibitors suppress aspects of the immune system by inhibiting superoxide production and this may, depending on the context, limit their effectiveness. In addition, the inability to modulate Nox4 activity and hydrogen peroxide formation may also promote increased cellular proliferation. Currently, the N-terminal ATP binding site is the major target of Hsp90 inhibitors, but novel Hsp90 inhibitors such as novobiocin (and its derivatives) and cisplatin have been shown to target other regions of Hsp90. Cochaperones of Hsp90 are also emerging as viable drug targets. The ability to inhibit distinct regions and potential functions of Hsp90 may reveal more information about how Hsp90 regulates Nox activity, may also facilitate selective inhibition of Hsp90-regulated pathways such as Nox activity, and ultimately, may improve therapeutic efficacy.

In summary, our results provide evidence that Hsp90 binds to the C-terminal region of Noxes1, 2, 3, and 5 and regulates the production of superoxide. Hsp90 is not necessary for the production of hydrogen peroxide from any of the Nox enzymes and does not affect the activity of Nox4. With the exception of Nox4, long-term inhibition of Hsp90 destabilizes Nox enzymes and results in a corresponding decrease in production of all ROS. The effects of superoxide, which are frequently difficult to reconcile given its rapid metabolism to other ROS, can be quite distinct from those of hydrogen peroxide on endpoints such as cell signaling and antimicrobial actions. Given the growing clinical utility of Hsp90 inhibitors, the consequences of a change in the balance of superoxide versus hydrogen peroxide might be of considerable significance.

\section{Acknowledgments}

The authors appreciate the technical support of Davin Jagnandan. Expertise for the BRET studies was provided by Dr. Nevin Lambert. This work was supported by grants from the NIH (HL085827, HL092446) and the AHA (EIA to D.F.).

\section{Author Disclosure Statement}

All authors declare that no competing financial interests exist.

\section{References}

1. Ambasta RK, Kumar P, Griendling KK, Schmidt H, Busse R, and Brandes RP. Direct interaction of the novel nox proteins with p22phox is required for the formation of a functionally active NADPH oxidase. J Biol Chem 279: 45935-45941, 2004.

2. Angers S, Salahpour A, Joly E, Hilairet S, Chelsky D, Dennis M, and Bouvier M. Detection of beta 2-adrenergic receptor dimerization in living cells using bioluminescence resonance energy transfer (BRET). Proc Natl Acad Sci U S A 97: 3684-3689, 2000.

3. Banfi B, Molnar G, Maturana A, Steger K, Hegedus B, Demaurex $\mathrm{N}$, and Krause $\mathrm{KH}$. A $\mathrm{Ca}(2+)$-activated $\mathrm{NADPH}$ oxidase in testis, spleen, and lymph nodes. J Biol Chem 276: 37594-37601, 2001.

4. Bedard $\mathrm{K}$ and Krause KH. The NOX family of ROSgenerating NADPH oxidases: physiology and pathophysiology. Physiol Rev 87: 245-313, 2007. 
5. Billecke SS, Bender AT, Kanelakis KC, Murphy PJ, Lowe ER, Kamada Y, Pratt WB, and Osawa Y. hsp90 is required for heme binding and activation of apo-neuronal nitric-oxide synthase: geldanamycin-mediated oxidant generation is unrelated to any action of hsp90. J Biol Chem 277: 20504-20509, 2002.

6. Bucci M, Roviezzo F, Cicala C, Sessa WC, and Cirino G. Geldanamycin, an inhibitor of heat shock protein 90 (Hsp90) mediated signal transduction has anti-inflammatory effects and interacts with glucocorticoid receptor in vivo. $\mathrm{Br} J$ Pharmacol 131: 13-16, 2000.

7. Cai $\mathrm{H}$ and Harrison DG. Endothelial dysfunction in cardiovascular diseases-the role of oxidant stress. Circ Res 87: 840-844, 2000.

8. Chabot F, Mitchell JA, Gutteridge JMC, and Evans TW. Reactive oxygen species in acute lung injury. Eur Respir J 11: 745-757, 1998.

9. Chadli A, Felts SJ, and Toft DO. GCUNC45 is the first Hsp90 co-chaperone to show alpha/beta isoform specificity. J Biol Chem 283: 9509-9512, 2008.

10. Chatterjee A, Snead C, Yetik-Anacak G, Antonova G, Zeng J, and Catravas JD. Heat shock protein 90 inhibitors attenuate LPS-induced endothelial hyperpermeability. Am J Physiol Lung Cell Mol Physiol 294: L755-L763, 2008.

11. Chavany C, Mimnaugh E, Miller P, Bitton R, Nguyen P, Trepel J, Whitesell L, Schnur R, Moyer J, and Neckers L. p185erbB2 binds to GRP94 in vivo. Dissociation of the p185erbB2/GRP94 heterocomplex by benzoquinone ansamycins precedes depletion of p185erbB2. J Biol Chem 271: 4974-4977, 1996.

12. Chen F and Fulton DJ. An inhibitor of protein arginine methyltransferases, 7,7'-carbonylbis(azanediyl)bis(4hydroxynaphthalene-2-sulfonic acid (AMI-1), is a potent scavenger of NADPH-oxidase-derived superoxide. Mol Pharmacol 77: 280-287, 2010.

13. Dikalov S, Landmesser U, and Harrison DG. Geldanamycin leads to superoxide formation by enzymatic and nonenzymatic redox cycling-implications for studies of hsp90 and endothelial cell nitric-oxide synthase. J Biol Chem 277: 25480-25485, 2002.

14. Ewing JF and Janero DR. Microplate superoxide dismutase assay employing a nonenzymatic superoxide generator. Anal Biochem 232: 243-248, 1995.

15. Felts SJ, Owen BAL, Nguyen P, Trepel J, Donner DB, and Toft DO. The hsp90-related protein TRAP1 is a mitochondrial protein with distinct functional properties. J Biol Chem 275: 3305-3312, 2000.

16. Garcia-Cardena G, Fan R, Shah V, Sorrentino R, Cirino G, Papapetropoulos A, and Sessa WC. Dynamic activation of endothelial nitric oxide synthase by Hsp90. Nature 392: 821-824, 1998.

17. Gratton JP, Fontana J, O'Connor DS, Garcia-Cardena G, McCabe TJ, and Sessa WC. Reconstitution of an endothelial nitric-oxide synthase (eNOS), hsp90, and caveolin-1 complex in vitro. Evidence that hsp90 facilitates calmodulin stimulated displacement of eNOS from caveolin-1. J Biol Chem 275: 22268-22272, 2000.

18. Griendling KK, Sorescu D, and Ushio-Fukai M. NAD(P)H oxidase: role in cardiovascular biology and disease. Circ Res 86: 494-501, 2000.

19. Helmcke I, Heumuller S, Tikkanen R, Schroder K, and Brandes RP. Identification of structural elements in Nox1 and Nox4 controlling localization and activity. Antioxid Redox Signal 11: 1279-1287, 2009.

20. Hon T, Lee HC, Hach A, Johnson JL, Craig EA, ErdjumentBromage $\mathrm{H}$, Tempst $\mathrm{P}$, and Zhang L. The Hsp70-Ydj1 mo- lecular chaperone represses the activity of the heme activator protein Hap1 in the absence of heme. Mol Cell Biol 21: 79237932, 2001.

21. Jacquier-Sarlin MR, Jornot L, and Polla BS. Differential expression and regulation of hsp70 and hsp90 by phorbol esters and heat shock. J Biol Chem 270: 14094-14099, 1995.

22. Jagnandan D, Church JE, Banfi B, Stuehr DJ, Marrero MB, and Fulton DJ. Novel mechanism of activation of NADPH oxidase 5. calcium sensitization via phosphorylation. J Biol Chem 282: 6494-6507, 2007.

23. Lambeth JD. NOX enzymes and the biology of reactive oxygen. Nat Rev Immunol 4: 181-189, 2004.

24. Liu H, Miller E, van de Water B, and Stevens JL. Endoplasmic reticulum stress proteins block oxidant-induced Ca2+ increases and cell death. J Biol Chem 273: 12858-12862, 1998.

25. Madrigal-Matute J, Lopez-Franco O, Blanco-Colio LM, Munoz-Garcia B, Ramos-Mozo P, Ortega L, Egido J, and Martin-Ventura JL. Heat shock protein 90 inhibitors attenuate inflammatory responses in atherosclerosis. Cardiovasc Res 86: 330-337, 2010.

26. Martyn KD, Frederick LM, von Loehneysen K, Dinauer MC, and Knaus UG. Functional analysis of Nox4 reveals unique characteristics compared to other NADPH oxidases. Cell Signal 18: 69-82, 2006.

27. Morishima Y, Peng HM, Lin HL, Hollenberg PF, Sunahara RK, Osawa Y, and Pratt WB. Regulation of cytochrome P450 2E1 by heat shock protein 90-dependent stabilization and CHIP-dependent proteasomal degradation. Biochemistry 44: 16333-16340, 2005.

28. Nisimoto $Y$, Jackson HM, Ogawa H, Kawahara T, and Lambeth JD. Constitutive NADPH-dependent electron transferase activity of the Nox4 dehydrogenase domain. Biochemistry 49: 2433-2442, 2010.

29. Pratt WB, Morishima Y, and Osawa Y. The Hsp90 chaperone machinery regulates signaling by modulating ligand binding clefts. J Biol Chem 283: 22885-22889, 2008.

30. Pratt WB, Morishima Y, Peng HM, and Osawa Y. Proposal for a role of the Hsp90/Hsp70-based chaperone machinery in making triage decisions when proteins undergo oxidative and toxic damage. Exp Biol Med (Maywood) 235: 278-289, 2010.

31. Pratt WB and Toft DO. Regulation of signaling protein function and trafficking by the hsp90/hsp70-based chaperone machinery. Exp Biol Med 228: 111-133, 2003.

32. Pritchard KA Jr., Ackerman AW, Gross ER, Stepp DW, Shi Y, Fontana JT, Baker JE, and Sessa WC. Heat shock protein 90 mediates the balance of nitric oxide and superoxide anion from endothelial nitric-oxide synthase. J Biol Chem 276: 17621-17624, 2001.

33. Serrander L, Cartier L, Bedard K, Banfi B, Lardy B, Plastre O, Sienkiewicz A, Forro L, Schlegel W, and Krause KH. NOX4 activity is determined by mRNA levels and reveals a unique pattern of ROS generation. Biochem J 406: 105-114, 2007.

34. Serrander L, Jaquet V, Bedard K, Plastre O, Hartley O, Arnaudeau S, Demaurex N, Schlegel W, and Krause KH. NOX5 is expressed at the plasma membrane and generates superoxide in response to protein kinase $\mathrm{C}$ activation. Biochimie 89: 1159-1167, 2007.

35. Smith JA. Neutrophils, host-defense, and inflammation-a double-edged-sword. J Leukoc Biol 56: 672-686, 1994.

36. Song Y, Cardounel AJ, Zweier JL, and Xia Y. Inhibition of superoxide generation from neuronal nitric oxide synthase by heat shock protein 90: implications in NOS regulation. Biochemistry 41: 10616-10622, 2002. 
37. Sumimoto H. Structure, regulation and evolution of Noxfamily NADPH oxidases that produce reactive oxygen species. FEBS J 275: 3249-3277, 2008.

38. Taipale M, Jarosz DF, and Lindquist S. HSP90 at the hub of protein homeostasis: emerging mechanistic insights. Nat Rev Mol Cell Biol 11: 515-528, 2010.

39. Tirone $\mathrm{F}$ and Cox JA. NADPH oxidase 5 (NOX5) interacts with and is regulated by calmodulin. FEBS Lett 581: 1202 1208, 2007.

40. Uma S, Hartson SD, Chen JJ, and Matts RL. Hsp90 is obligatory for the heme-regulated eIF-2alpha kinase to acquire and maintain an activable conformation. J Biol Chem 272: 11648-11656, 1997.

41. Valko M, Leibfritz D, Moncol J, Cronin MTD, Mazur M, and Telser J. Free radicals and antioxidants in normal physiological functions and human disease. Int J Biochem Cell Biol 39: 44-84, 2007.

42. Vasquez-Vivar J, Martasek P, Hogg N, Karoui H, Masters BS, Pritchard KA Jr., and Kalyanaraman B. Electron spin resonance spin-trapping detection of superoxide generated by neuronal nitric oxide synthase. Methods Enzymol 301: 169-177, 1999.

43. Vega VL and De Maio A. Increase in phagocytosis after geldanamycin treatment or heat shock: role of heat shock proteins. J Immunol 175: 5280-5287, 2005.

44. Venema RC, Venema VJ, Ju H, Harris MB, Snead C, Jilling T, Dimitropoulou C, Maragoudakis ME, and Catravas JD. Novel complexes of guanylate cyclase with heat shock protein 90 and nitric oxide synthase. Am J Physiol Heart Circ Physiol 285: H669-H678, 2003.

45. von Lohneysen K, Noack D, Wood MR, Friedman JS, and Knaus UG. Structural insights into Nox4 and Nox2: motifs involved in function and cellular localization. Mol Cell Biol 30: 961-975, 2010.

46. Whitesell L and Lindquist SL. HSP90 and the chaperoning of cancer. Nat Rev Cancer 5: 761-772, 2005.

47. Yoshida M and Xia Y. Heat shock protein 90 as an endogenous protein enhancer of inducible nitric-oxide synthase. J Biol Chem 278: 36953-36958, 2003.

48. Zhang Q, Church JE, Jagnandan D, Catravas JD, Sessa WC, and Fulton D. Functional relevance of Golgi- and plasma membrane-localized endothelial NO synthase in reconstituted endothelial cells. Arterioscler Thromb Vasc Biol 26: 1015-1021, 2006.
49. Zhang Q, Malik P, Pandey D, Gupta S, Jagnandan D, Belin de Chantemele E, Banfi B, Marrero MB, Rudic RD, Stepp DW, and Fulton DJ. Paradoxical activation of endothelial nitric oxide synthase by NADPH oxidase. Arterioscler Thromb Vasc Biol 28: 1627-1633, 2008.

Address correspondence to: Dr. David J.R. Fulton Vascular Biology Center Medical College of Georgia 1459 Laney Walker Blvd.

Augusta, GA 30912

E-mail: dfulton@mcg.edu

Date of first submission to ARS Central, September 24, 2010; date of final revised submission, December 17, 2010; date of acceptance, January 1, 2011.

\section{Abbreviations Used}

17-AAG =17-allylamino-17-demethoxygeldanamycin $\mathrm{BRET}=$ bioluminescence resonance energy transfer

DMEM $=$ Dulbecco's Modified Eagle's Medium $\mathrm{GA}=$ geldanamycin

Hsp90 $=$ heat-shock protein 90

$\mathrm{IgG}=$ immunoglobulin

MCLA = 2-methyl-6-(4-methoxyphenyl)-3, 7-dihydroimidazo[1,2-a]pyrazin-3-one, hydrochloride

MOPS $=3-(N$-morpholino $)$ propanesulfonic acid Nox $=$ NADPH oxidase

$\mathrm{PKC}=$ protein kinase $\mathrm{C}$

PMA $=$ phorbol 12-myristate 13-acetate

$\mathrm{PMS}=$ phenazine methosulfate

$\mathrm{RAD}=$ radicicol

RLU $=$ relative light units

RLUC $=$ Renilla luciferase

ROS $=$ reactive oxygen species

$\mathrm{SOD}=$ superoxide dismutase 
